\title{
ASSOCIATION OF INTRON-2 VARIABLE NUMBERS OF AN 86-BP TANDEM REPEAT- POLYMORPHISMS OF INTERLEUKIN-1 RECEPTOR ANTAGONIST GENE AND IDIOPATHIC RECURRENT SPONTANEOUS ABORTION
}

\author{
Marco Antonio Avila-Vergara ${ }^{1,2}$, Felipe de Jesús Peraza-Garay ${ }^{*}$, Noemí Meraz-Cruz 4 , \\ Cesar Hernandez-Guerrero ${ }^{5}$, Berenice Palacios-Gonzalez ${ }^{4}$, Felipe Vadillo-Ortega ${ }^{4,6,7}$
}

${ }^{1}$ Department of Obstetrics and Gynecology, Hospital Regional No. 1, Instituto Mexicano del Seguro Social, Mexico City, Mexico; ${ }^{2}$ Department of Clinical Sciences, School of Medicine and ${ }^{3}$ Department of Biostatistics, Health Sciences Center for Research and Teaching, Universidad Autónoma de Sinaloa, Sin., Mexico; ${ }^{4}$ Universidad Nacional Autónoma de México School of Medicine, Branch at Instituto Nacional de Medicina Genómica, Mexico City, Mexico; ${ }^{5}$ Health Department, Universidad Iberoamericana Ciudad de México, Mexico City, Mexico; ${ }^{6}$ Perinatology Research Branch, Program for Perinatal Research and Obstetrics, Division of Intramural Research, Eunice Kennedy Shriver National Institute of Child Health and Human Development, NICHD/NIH/DHHS, Bethesda, Maryland, and Detroit, Michigan; ${ }^{7}$ Department of Obstetrics and Gynecology, Wayne State University School of Medicine, Detroit, Michigan. USA

\begin{abstract}
Background: It has been proposed that abnormal modulation of inflammatory response is involved in the physiopathology of idiopathic recurrent spontaneous abortion (iRSA). Factors that may participate in this process include the genetic background such as carrying specific polymorphisms of genes with functional effects. Objective: The objective is to study the association between iRSA and the frequency of intron-2 variable number tandem repeat-polymorphisms of interleukin-1 receptor antagonist gene (ILIRN). Methods: We conducted a case-control study including 108 women with iRSA and 103 controls. Five allelic variants of ILIRN were determined by polymerase chain reaction (PCR) product length analysis. Results: The most frequent ILIRN allele in this population was ILIRN*1, which was present in $78 \%$ of cases and $94 \%$ of controls, and allele ILIRN*2, in $45(20.8 \%)$ cases and $12(5.8 \%)$ controls. Allele ILIRN*2 was significantly associated with iRSA (odds ratio = $4.28,95 \%$ confidence interval 2.2-8.4; $\mathrm{p}=0.000$ ). Conclusion: Carrying allele IL $1 R N^{*} 2$ had a strong association with iRSA in Mexican women. This polymorphism codifies for a low-function protein, which may allow for increased activity of IL-1 pro-inflammatory axis in iRSA. (REV INVES CLIN. 2018;70:96-102)
\end{abstract}

Key words: Recurrent spontaneous abortion. Variable numbers of an 86-bp tandem repeat polymorphisms. Interleukin-1 receptor antagonist.

Corresponding author:

*Felipe Vadillo-Ortega

C.S. Mott Center for Human Growth

and Development

275 E Hancock St

Detroit, MI, 48201 USA

Received for publication: 16-01-2018

Accepted for publication: 02-03-2018

doi: $10.24875 / R I C .18002485$ 


\section{INTRODUCTION}

Intrauterine induction of the inflammatory response is associated with a very specific and tightly regulated window during embryo implantation ${ }^{1}$. Abnormal inflammatory responses have been related to loss of gestation ${ }^{2,3}$ including idiopathic recurrent spontaneous abortion (iRSA). IRSA is defined as the spontaneous loss of two or more clinical pregnancies before 22 completed weeks of gestational age in which no associated clinical factors are identified ${ }^{4,5}$.

Physiopathology of this reproductive disorder is still incompletely understood; however, different evidence points to the participation of mediators of inflammation in the mechanisms of damage. Interleukin-1 $\beta$ (IL-1 $\beta$ ) is a potent pro-inflammatory cytokine that initiates and amplifies a wide variety of effects associated with innate immunity and host responses to microbial invasion and tissue injury ${ }^{6}$. Expression of this cytokine during implantation and early placentation has been associated with successful pregnancy both in animal models and humans 7,8 .

On the other hand, overexpression of IL-1 $\beta$ has been related to the induction of miscarriage ${ }^{9,10}$. Functional effects of IL- $1 \beta$ are regulated, among other factors, by the presence of the IL-1 receptor antagonist (IL-1ra), a molecule that selectively blocks the actions of equimolar concentrations of IL-1 cytokine family ${ }^{11,12}$. An imbalance favoring cytokine concentration over its natural inhibitor has been proposed as an explanation to abnormal expression of IL- $1 \beta$ effects, such as in arthritis ${ }^{13}$, autoinflammatory disease $^{14}$ and sepsis ${ }^{15}$.

The ILIRN gene, located on the human chromosome $2 q 14$ region $^{16}$, encodes IL-1ra and the presence of several functional polymorphisms has been described. Among them, ILIRN intron 2 polymorphisms that include 2-6 variable numbers of an 86-bp tandem repeat (VNTR) sequence have been identified. The most common polymorphism is allele 1 (frequency $0.736)^{17}$. There is evidence that carrying allele 2 , the second most common polymorphism, is associated to increased bioactivity of IL-1 in iRSA, as well as in other perinatal outcomes ${ }^{18-20}$. However, other publications have not found such relationship ${ }^{21,22}$.
In this paper, we evaluate the association between intron 2 polymorphisms of IL-1 receptor antagonist gene (ILIRN) and iRSA in a sample of Mexican women.

\section{MATERIAL AND METHODS}

A case-control clinical trial was conducted at the Regional Hospital No. 1, Instituto Mexicano del Seguro Social (Mexican Social Security Institute), in Culiacán, Sinaloa, Mexico. The local Investigation Committee approved this project (Register R-1998-2501-01 IMSS). Samples were collected from January 2010 to September 2014.

\section{Patients}

We used the definition and clinical classification of recurrent spontaneous abortion (RSA) from the American Society for Reproductive Medicine and the ESHRE Special Interest Group, Early Pregnancy, stating that RSA is defined when two or more pregnancy losses before 20 weeks of gestation occur ${ }^{4,5}$. Cases were women with a clinical history of RSA in which no associated cause explaining miscarriage was identified during clinical protocol and classified as iRSA. Clinical protocol to rule out associated conditions included general studies (hematology, clinical chemistry, urinalysis, and coagulation tests), karyotype of both members of the couple, hormonal profile (follicle-stimulating hormone, luteinizing hormone, estradiol, androstenedione, prolactin, and thyroid-stimulating hormone), autoimmune conditions (lupus anticoagulant, antiphospholipid antibodies, and antinuclear antibodies), pelvic ultrasound, hysterosalpingography, and infections panel (toxoplasma, cytomegalovirus, rubella, herpes, Mycoplasma hominis, and Ureaplasma urealyticum). Confirmation of miscarriage included identification of embryo or placental tissues by histopathology.

Women with no medical history of miscarriage and at least two consecutive pregnancies delivering at term with normal spontaneous labor and healthy newborn were included as controls. Women attending postpartum follow-up and who had a normal course during pregnancy and delivery, including normal routine laboratory examinations and no evidence of other pathologies in the clinical records, were invited to participate and granted signed consent. 
Table 1. Clinical characteristics of iRSA patients and controls

\begin{tabular}{|c|c|c|c|}
\hline \multirow[t]{2}{*}{ Clinical characteristics } & \multicolumn{2}{|c|}{ Group } & $p$ value \\
\hline & $\begin{array}{c}\text { iRSA* } \\
(n=108)\end{array}$ & $\begin{array}{l}\text { Controls } \\
(n=103)\end{array}$ & $\frac{\sqrt{c}}{\frac{\hbar}{\sigma}}$ \\
\hline Age in years & $\begin{array}{c}30.9 \pm 4.6 \\
(18-49)\end{array}$ & $\begin{array}{l}29.3 \pm 2.6 \\
(23-37)\end{array}$ & $0.005^{\circ}$ \\
\hline Parity & $\begin{array}{l}3.4 \pm 1.3 \\
\quad(1-7)\end{array}$ & $\begin{array}{l}2.8 \pm 0.7 \\
(2-3)\end{array}$ & 0.000 \\
\hline Deliveries & $\begin{array}{c}1.2 \pm 1.2 \\
(0-6)\end{array}$ & $\begin{array}{c}2.8 \pm 0.7 \\
(2-3)\end{array}$ & 0.000 \\
\hline Abortions & $\begin{array}{l}2.2 \pm 1.4 \\
\quad(2-4)\end{array}$ & 0 & $\mathrm{NA}$ \\
\hline $\begin{array}{l}\text { Gestational age at abortion } \\
\text { (weeks) }\end{array}$ & $\begin{array}{l}15.45 \pm 2.6 \\
(8-20)\end{array}$ & NA & NA \\
\hline
\end{tabular}

*iRSA was defined when two or more pregnancy losses before 20 weeks of gestation occurred.

Mean \pm SD, (range).

NA: not applicable, iRSA: idiopathic recurrent spontaneous abortion, SD: standard deviation.

\section{Polymorphism identification}

A sample of $5 \mathrm{~mL}$ of blood was obtained and processed for DNA extraction and purification using DNeasy Blood and Tissue kits (Qiagen, Germantown, $\mathrm{MD}$ ). Purified DNAs were stored at $-80^{\circ} \mathrm{C}$ until assayed. Polymorphism identification was done using the protocol of Genc et al. ${ }^{23}$, which briefly consists of DNA amplification with a PCR protocol of 35 cycles ( $60 \mathrm{~s} 94^{\circ} \mathrm{C}, 60 \mathrm{~s} 60^{\circ} \mathrm{C}$, and $60 \mathrm{~s} 72^{\circ} \mathrm{C}$ ), using the pair of primers: Forward: $5^{\prime}$-CTCAGCAACACTCCTAT-3' and reverse: $5^{\prime}$-TCCTGGTCGCAGGTAA-3'. Amplification products were analyzed in $1.5 \%$ agarose gels. This technique allows the identification of five alleles ${ }^{17}$ : allele ILIRN* 1 was identified as a product of 410-bp band (four copies of the 86-bp repeat); allele ILIRN*2 was a 240-bp band (two repeats); allele IL$1 R N * 3$ was a 500-bp band (five repeats); allele IL$1 R N^{*} 4$ was a 325 -bp band (three repeats); and allele ILIRN*5 was a 595-bp band (six repeats).

\section{Statistical analysis}

Hardy-Weinberg equilibrium was verified in the control group. The association between specific alleles and genotypes with iRSA was evaluated using Chisquare test, and odds ratio (OR) and $95 \%$ confidence interval $(\mathrm{Cl})$ were calculated. Values of $\mathrm{p}<0.05$ were considered as statistically significant.

\section{RESULTS}

We included 108 women diagnosed with iRSA (cases) and 103 controls. The clinical characteristics of patients are shown in table 1.

Hardy-Weinberg equilibrium was demonstrated in the control group $(p=0.242)$. The most frequent genotype was homozygous ILIRN*1/1, which was present in 69 cases ( $64.4 \%$ ) and 92 controls $(89.3 \%)$. Genotype ILIRN*1/2 and ILIRN*2/2 were present in $31(28.9 \%)$ and 7 (6.5\%) cases and in 10 (9.7\%) and $1(0.9 \%)$ controls, respectively. No ILIRN*3 and 4 were found in these patients. Only one case of $1 / 5$ polymorphism was found in the whole iRSA group. Carrying genotype $I L 1 R N^{*} 1 / 2$ or $\operatorname{LL} 1 R N^{*} 2 / 2$, compared with $I L 1 R N^{*} 1 / 1$ was significantly associated with $\mathrm{iRSA}(\mathrm{OR}=4.61,95 \% \mathrm{Cl} 2.2-9.6 ; \mathrm{p}=0.001)$ (Table 2). 
Table 2. Association by genotype

\begin{tabular}{|c|c|c|c|c|c|c|}
\hline \multirow[t]{2}{*}{ Group } & \multicolumn{3}{|c|}{ Genotype } & \multicolumn{2}{|c|}{ Statistical analysis* } & \multirow{2}{*}{$\frac{}{\mathrm{Cl}} 95 \%$} \\
\hline & $1 / 1$ & $1 / 2$ & $2 / 2$ & $p$ value & OR & \\
\hline Control $(n=103)$ & $92(89.3 \%)$ & $10(9.7 \%)$ & $1(0.9 \%)$ & & & $\frac{1}{(0)}$ \\
\hline iRSA $(n=107)$ & $69(64.4 \%)$ & $31(28.9 \%)$ & $7(6.5 \%)$ & 0.001 & 4.61 & $2.2-9.6$ \\
\hline
\end{tabular}

*Comparing genotype $1 / 1$ against any genotype containing allele 2 , using control group as contrast. One case with genotype $1 / 5$ was excluded from analysis.

OR: odds ratio, $\mathrm{Cl}$ : confidence interval, iRSA: idiopathic recurrent spontaneous abortion.

Table 3. Association by allele

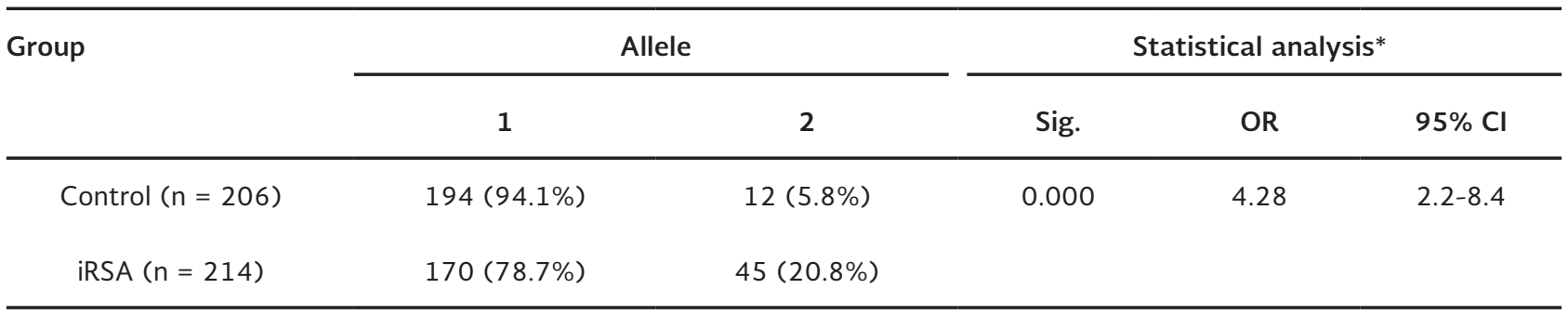

*Comparing allele 1 versus Allele 2, using control group as contrast. One case with allele 5 was excluded from analysis.

OR: odds ratio, $\mathrm{Cl}$ : confidence interval, iRSA: idiopathic recurrent spontaneous abortion.

Figure 1. Polymerase chain reaction (PCR) products evaluation. Purified DNAs from five patients were subjected to PCR amplification of IL1RN intron-2 using the protocol described in Material and Methods and analyzed by gel electrophoresis. Allele ILIRN*1 appears as a product of 412 bp and Allele IL1RN*2 appears as a band of $240 \mathrm{bp}$. Lanes 1 and 3 show IL1RN*1 homozygosity, Lanes 2 and 4 show 1/2 heterozygosity, and Lane 5 shows IL1RN*2 homozygosity. Lane 8 shows 100-bp ladder molecular weight marker.

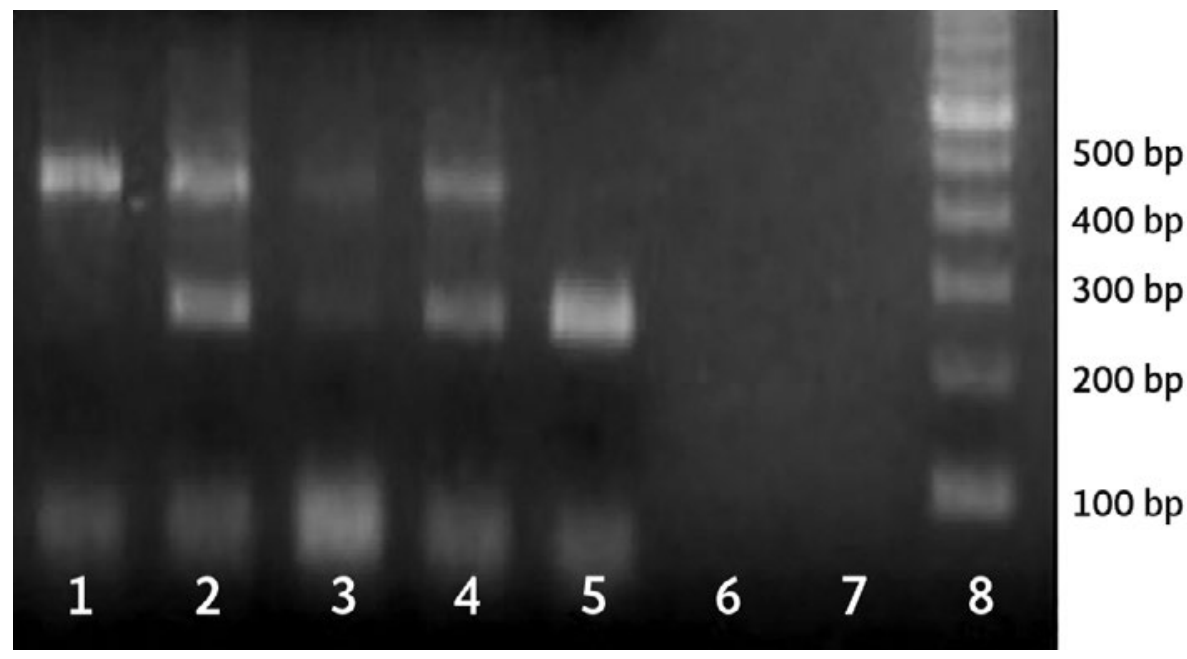

As expected, the most frequent allele in this population was allele 1 , present in 170 (78.7\%) cases and 194 ( $94.1 \%$ ) controls. Allele 2 was present in 45
(20.8\%) cases and 12 (5.8\%) controls. Carrying allele IL $1 R N * 2$ compared to allele IL $1 R N^{*} 1$ was significantly associated with iRSA ( $p=0.000$ ) (Table 3 ). Figure 1 
shows typical results of the electrophoresis of PCR products, including alleles 1 and 2 .

Logistic regression analysis revealed that carrying the allele IL1RN*2 best fits the dominant model.

\section{DISCUSSION}

Mechanisms of iRSA are still unknown and must be complex. Involvement of an uncontrolled inflammatory response as part of these mechanisms is plausible, and a key participation of IL-1 $\beta$ has been suggested by several authors. IL-1 $\beta$ modulates at least three different early events of implantation: Regulation of trophoblast motility ${ }^{24}$, regulation of the interaction of the trophoblast with endometrium ${ }^{25}$, and direct inhibition of decidualization ${ }^{26,27}$.

These effects appear to be mediated by regulating cyclooxygenase- 2 expression and using prostaglandins as secondary signals ${ }^{28}$. Any condition that alters the physiological balance between IL-1, and its natural inhibitor IL-1ra may result in detrimental effects of the cytokine.

Studies in animal models have shown that implantation may be blocked by adding an excess of IL-1 $\mathrm{ra}^{29}$. Further characterization of the extent and type of inflammatory response accompanying iRSA is extremely difficult but can be partially addressed using a serial sampling of plasma or cervicovaginal swabs in a cohort of early pregnant women already identified with iRSA.

This may be used in the future for the development of new iRSA biomarkers or for the identification of potential targets for anti-inflammatory therapeutics.

Genetic background may contribute to the final balance of IL-1 since the presence of alternative alleles of ILIRN results in the generation of protein products with different bioactivity. Carriage of the ILIRN*2 variant has been linked to the decreased bioactivity of the IL-1ra manifested as the decreased concentration of the protein ${ }^{30}$ or decreased affinity to the IL-1 receptor.

Decreased mRNA expression of IL-1ra has been demonstrated in cell lines carrying allele- $2^{31}$. In addition, some authors have demonstrated increased secretion of $\mathrm{IL}-1 \beta$ in association to the presence of $\mathrm{IL}$ $1 R N^{*} 2$ allele ${ }^{32}$ and increased production of $\mathrm{IL}-1$ and decreased IL-1ra on in vitro stimulation ${ }^{33}$, pointing to a cross-regulation between the receptor antagonist and cytokine expression ${ }^{34}$.

A more general correlation between ILIRN*2 allele and presence of autoinflammatory disease strongly supports a role in the control of the inflammatory response, and iRSA may be included within this group of diseases ${ }^{15,35}$. New evidence from murine models has shown prevention of miscarriage by blocking IL- $1 \beta^{36}$.

We found a frequency of ILIRN genotypes and alleles in Mexican women that is similar to frequencies described in other Hispanic populations but different to Caucasic, Chinese, and Afro-American women ${ }^{37,38 .}$

We found an association between carrying $I L 1 R N^{*} 2$ allele and development of iRSA, in agreement to previous findings in diverse populations ${ }^{19,39}$ and in agreement with a recent meta-analysis ${ }^{40}$. Our data support the dominant transmission of this allele, but the sample size for genotype $2 / 2$ was too small to state a final conclusion.

In this paper, we provide additional evidence of an association between iRSA and carrying an $I L 1 R N$ allele that has been linked with decreased function of the specific inhibitor of the IL-1 family, which may result in increased bioactivity of the cytokines.

The relevance of ILIRN polymorphism identification is beyond the exclusive statistical association with iRSA, since we have enough information on the functional relevance of carrying $I L 1 R N * 2$ variant that has been linked to the increased bioactivity of IL$1^{18,20,34,41}$. Other studies did not confirm an association between ILIRN alleles and RSA $21,22,42, \overline{43}$.

These contradictory results may be explained by several reasons. First, the prevalence of polymorphisms of interest is variable among different populations ${ }^{37}$, and hence, statistical association may change. Second, the clinical definition of RSA is still under debate in the international literature ${ }^{43,44}$ and a non-unified criteria selection for patients may introduce a bias that may explain these contradictory findings. 
The strong association we found in this report between carrying the IL1RA*2 allele and IRSA opens an opportunity to develop new biomarkers for the evaluation of future risk in women presenting spontaneous abortion of unknown origin. The use of these and other genomic tools will only carry significative benefits in the arena of widely used and well-structured clinical protocols for adequate stratification of patients suffering from spontaneous abortion, something that is still in the development for iRSA.

It is important to emphasize that a single gene variant such as ILIRN*2 cannot be the direct cause of iRSA, but a strong evidence that innate immune mechanisms plays a role in the pathogenesis of this disease of human reproduction.

\section{ACKNOWLEDGMENTS}

We recognize the technical help of Edna Elisa Garcia Vences.

\section{REFERENCES}

1. Mor G, Cardenas I, Abrahams V, Guller S. Inflammation and pregnancy: the role of the immune system at the implantation site. Ann N Y Acad Sci. 2011:1221:80-7.

2. Jabbour HN, Sales KJ, Catalano RD, Norman JE. Inflammatory pathways in female reproductive health and disease. Reproduction. 2009;138:903-19.

3. Weiss G, Goldsmith LT, Taylor RN, Bellet D, Taylor HS. Inflammation in reproductive disorders. Reprod Sci. 2009;16:216-29.

4. Zegers-Hochschild F, Adamson GD, Dyer S, et al. The international glossary on infertility and fertility care, 2017. Fertil Steril. 2017;108:393-406.

5. Kolte AM, Bernardi LA, Christiansen OB, et al. Terminology for pregnancy loss prior to viability: a consensus statement from the ESHRE early pregnancy special interest group. Hum Reprod. 2015;30:495-8.

6. Casanova JL, Abel L, Quintana-Murci L. Human TLRs and IL1 Rs in host defense: natural insights from evolutionary, epidemiological, and clinical genetics. Annu Rev Immunol. 2011; 29:447-91.

7. Imakawa K, Chang KT, Christenson RK. Pre-implantation conceptus and maternal uterine communications: molecular events leading to successful implantation. J Reprod Dev. 2004:50:155-69

8. De los Santos MJ, Mercader A, Francés A, et al. Role of endometrial factors in regulating secretion of components of the immunoreactive human embryonic interleukin-1 system during embryonic development. Biol Reprod. 1996;54:563-74.

9. Sarno J, Schatz F, Huang SJ, Lockwood C, Taylor HS. Thrombin and interleukin-1beta decrease HOX gene expression in human first trimester decidual cells: implications for pregnancy loss. Mol Hum Reprod. 2009;15:451-7.

10. Giannubilo SR, Landi B, Pozzi V, et al. The involvement of inflammatory cytokines in the pathogenesis of recurrent miscarriage. Cytokine. 2012;58:50-6.

11. Dinarello CA, Thompson RC. Blocking IL-1: interleukin 1 receptor antagonist in vivo and in vitro. Immunol Today. 1991; 12:404-10.
12. Lennard AC. Interleukin-1 receptor antagonist. Crit Rev Immunol. 1995;15:77-105.

13. Arend WP, Gabay C. Physiologic role of interleukin-1 receptor antagonist. Arthritis Res. 2000;2:245-8.

14. Aksentijevich I, Masters SL, Ferguson PJ, et al. An autoinflammatory disease with deficiency of the interleukin-1-receptor antagonist. N Engl J Med. 2009;360:2426-37.

15. Witkin SS, Gerber S, Ledger WJ. Influence of interleukin-1 receptor antagonist gene polymorphism on disease. Clin Infect Dis. 2002;34:204-9

16. Patterson D, Jones $C$, Hart I, et al. The human interleukin-1 receptor antagonist (ILIRN) gene is located in the chromosome 2q14 region. Genomics. 1993;15:173-6.

17. Tarlow JK, Blakemore Al, Lennard A, et al. Polymorphism in human $\mathrm{IL}-1$ receptor antagonist gene intron 2 is caused by variable numbers of an $86-b p$ tandem repeat. Hum Genet. 1993;91:403-4.

18. Perni SC, Vardhana S, Tuttle SL, et al. Fetal interleukin-1 receptor antagonist gene polymorphism, intra-amniotic interleukin1 beta levels, and history of spontaneous abortion. Am J Obstet Gynecol. 2004;191:1318-23.

19. Unfried G, Tempfer C, Schneeberger C, et al. Interleukin 1 receptor antagonist polymorphism in women with idiopathic recurrent miscarriage. Fertil Steril. 2001;75:683-7.

20. Witkin SS, Vardhana S, Yih M, et al. Polymorphism in intron 2 of the fetal interleukin-1 receptor antagonist genotype influences midtrimester amniotic fluid concentrations of interleukin-1beta and interleukin-1 receptor antagonist and pregnancy outcome. Am J Obstet Gynecol. 2003;189:1413-7.

21. Dai MZ, Pan YQ, Xu DP, et al. IL-1 receptor antagonist gene polymorphism in idiopathic recurrent spontaneous abortion in a chinese han population. Int J Immunogenet. 2010:37:393-6.

22. Levrant S, Coulam CB, Jeyendran RS. Interleukin 1 receptor antagonist gene polymorphisms are not risk factors for recurrent pregnancy loss: evaluation of couples. Am JReprod Immunol. 2008;60:224-8.

23. Genç MR, Gerber S, Nesin M, Witkin SS. Polymorphism in the interleukin-1 gene complex and spontaneous preterm delivery. Am J Obstet Gynecol. 2002;187:157-63.

24. Prutsch $N$, Fock V, Haslinger $P$, et al. The role of interleukin-1 $\beta$ in human trophoblast motility. Placenta. 2012;33:696-703.

25. Flamigni $C$, Bulletti $C$, Polli $V$, et al. Factors regulating interaction between trophoblast and human endometrium. Ann $\mathrm{N} \mathrm{Y}$ Acad Sci. 1991;622:176-90.

26. Kariya M, Kanzaki H, Takakura K, et al. Interleukin-1 inhibits in vitro decidualization of human endometrial stromal cells. J Clin Endocrinol Metab. 1991;73:1170-4

27. Frank GR, Brar AK, Jikihara H, Cedars MI, Handwerger S. Interleukin-1 beta and the endometrium: an inhibitor of stromal cell differentiation and possible autoregulator of decidualization in humans. Biol Reprod. 1995;52:184-91.

28. Kniss DA, Zimmerman PD, Garver CL, Fertel RH. Interleukin-1 receptor antagonist blocks interleukin-1-induced expression of cyclooxygenase-2 in endometrium. Am J Obstet Gynecol. 1997; 177:559-67.

29. Simón C, Valbuena D, Krüssel J, et al. Interleukin-1 receptor antagonist prevents embryonic implantation by a direct effect on the endometrial epithelium. Fertil Steril. 1998;70:896-906.

30. Danis VA, Millington M, Hyland VJ, Grennan D. Cytokine production by normal human monocytes: inter-subject variation and relationship to an IL-1 receptor antagonist (IL-1Ra) gene polymorphism. Clin Exp Immunol. 1995;99:303-10.

31. Dewberry $\mathrm{R}$, Holden $\mathrm{H}$, Crossman D, Francis S Interleukin-1 receptor antagonist expression in human endothelial cells and atherosclerosis. Arterioscler Thromb Vasc Biol. 2000;20: 2394-400

32. Hurme M, Santtila S. IL-1 receptor antagonist (IL-1Ra) plasma levels are co-ordinately regulated by both IL-1Ra and IL-1beta genes. Eur J Immunol. 1998;28:2598-602.

33. Buchs N, di Giovine FS, Silvestri T, et al. IL-1B and IL-1Ra gene polymorphisms and disease severity in rheumatoid arthritis: interaction with their plasma levels. Genes Immun. 2001;2: 222-8.

34. Santtila S, Savinainen K, Hurme M. Presence of the $\mathrm{IL}-1$ RA allele 2 (IL $1 R N^{*} 2$ ) is associated with enhanced IL-1beta production in vitro. Scand J Immunol. 1998;47:195-8

35. Arend WP. The balance between IL-1 and IL-1Ra in disease. Cytokine Growth Factor Rev. 2002;13:323-40.

36. Wang J, Wu F, Xie Q, et al. Anakinra and etanercept prevent embryo loss in pregnant nonobese diabetic mice. Reproduction. 2015;149:377-84 
37. Nguyen DP, Genc M, Vardhana S, et al. Ethnic differences of polymorphisms in cytokine and innate immune system genes in pregnant women. Obstet Gynecol. 2004;104:293-300.

38. Xu DP, Ruan YY, Pan YQ, et al. VNTR polymorphism of human ILIRN in Chinese Han and she ethnic populations. Int J Immunogenet. 2011;38:13-6.

39. Karhukorpi J, Laitinen T, Kivelä H, Tiilikainen A, Hurme M. IL-1 receptor antagonist gene polymorphism in recurrent spontaneous abortion. J Reprod Immunol. 2003;58:61-7.

40. Nair RR, Khanna A, Singh K. Association of interleukin 1 receptor antagonist (ILIRN) gene polymorphism with recurrent pregnancy loss risk in the north Indian population and a metaanalysis. Mol Biol Rep. 2014;41:5719-27.
41. Gremlich S, Fratta S, Rebellato $E$, et al Interleukin-1 receptor antagonist gene (IL-1RN) polymorphism is a predictive factor of clinical pregnancy after IVF. Hum Reprod. 2008; 23:1200-6

42. Linjawi S, Li TC, Laird S, Blakemore A. Interleukin-1 receptor antagonist and interleukin-1 beta polymorphisms in women with recurrent miscarriage. Fertil Steril. 2005;83:1549-52.

43. Choi YK, Kwak-Kim J. Cytokine gene polymorphisms in recurrent spontaneous abortions: a comprehensive review. Am J Reprod Immunol. 2008;60:91-110.

44. Saravelos SH, Li TC. Unexplained recurrent miscarriage: how can we explain it? Hum Reprod. 2012;27:1882-6. 